\title{
Hubungan Peningkatan Indeks Massa Tubuh dengan Kejadian Kolelitiasis di Bagian Bedah Digestif RSI Siti Rahmah Padang Periode Januari-Juni 2018
}

\author{
Nurhikmah, ${ }^{1}$, Efriza ${ }^{2}$, Abdullah, $\mathrm{D}^{3}$ \\ ${ }^{1}$ Mahasiswa Fakultas Kedokteran Universitas Baiturrahmah, Padang, Indonesia \\ E-mail : nurhikmahrzk@gmail.com \\ ${ }^{2}$ Bagian Histologi Fakultas Kedokteran Baiturrahmah, Padang, Indonesia \\ ${ }^{3}$ Bagian Farmakologi Fakultas Kedokteran Baiturrahmah, Padang, Indonesia
}

\begin{abstract}
Abstrak
Latar belakang: Kolelitiasis merupakan timbunan kristal yang terbentuk oleh gabungan beberapa unsur dari cairan empedu dalam kantung empedu. Penderita kolelitiasis di populasi umum 5\%, meningkat signifikan pada populasi dengan Indeks Massa Tubuh (IMT) menjadi 45\%. Kolelitiasis di Indonesia kurang mendapat perhatian karena sering asimptomatik dan kesalahan diagnosis. Tujuan: Penelitian ini bertujuan untuk mengetahui hubungan peningkatan IMT dengan kejadian kolelitiasis di instalasi bedah RSI Siti Rahmah Padang periode Januari-Juni 2018. Metode: Penelitian ini merupakan penelitian analitik observasional dengan desain penelitian cross sectional. Analisis data menggunakan analisis univariat untuk mengetahui distribusi frekuensi dan analisis bivariat untuk mengetahui keterkaiatan variabel. Hasil: Didapatkan jenis kelamin perempuan terbanyak pada kolelitiasis yaitu 11 orang (57,9\%), kelompok usia 40-49 tahun tertinggi pada pasien kolelitiasis yaitu 36,8\% dan terdapat hubungan antara peningkatan IMT dengan kejadian kolelitiasis $(\mathrm{p}=0.001)$. Kesimpulan: Terdapat hubungan antara peningkatan IMT dengan kejadian kolelitiasis $(\mathrm{p}=0.001)$.
\end{abstract}

Katakunci - Cairan empedu, empedu, Indeks Massa Tubuh, kolelitiasis

\section{Abstract}

Background: Cholelithiasis is a pile of crystals formed by a combination of several elements from the bile in the gallbladder. The incidence of cholelithiasis has been reported to be 5\% in the general population, while it is significantly increased in overweight and obese population reaching 45\%. In Indonesia there is less attention because it is often asymptomatic and misdiagnosed. Objective: The aim of this study was to know the relation of increased BMI with the incidence of cholelithiasis at the surgical department of RSI Siti Rahmah Padang within the period in January-June 2018. Method: An observational analytic study was done using the cross sectional approach. Data analysis using univariate and bivariat analysis. Result: The result of this study, out of 44 patients, the highest gender with cholelithiasis was found in female with 11 people (57.9\%), the highest age in cholelithiasis was found 40-49 years 36,8\% and there was association between the increased BMI and the incidence of cholelithiasis $(p=0.001)$. Conclusion: there was association between the increased BMI and the incidence of cholelithiasis $(p=0.001)$.

Keywords-Body Mass index (BMI), cholelithiasis, gall, gallblader. 


\section{Pendahuluan}

Insiden kolelitiasis telah dilaporkan $5 \%$ di populasi umum, meningkat secara signifikan pada populasi dengan IMT meningkat mencapai 45\%. ${ }^{1}$ Prevalensi kolelitiasis dilaporkan di negara-negara Barat berkisar antara $10-15 \%{ }^{2}$

Kejadian kolelitiasis di negara Asia 3\%-15\% lebih rendah dibandingan negara barat. ${ }^{3}$ Kasus kolelitiasis di Indonesia kurang mendapat perhatian karena sering sekali asimtomatik sehingga sulit di deteksi atau sering terjadi kesalahan diagnosis. Penelitian yang pernah dilakukan di Medan tahun 2011, didapatkan 82 kasus kolelitiasis. ${ }^{4}$

Penelitian yang dilakukan oleh Liu et al tahun 2018 didapatkan hasil kasus kolelitiasis pada pasien perempuan sebanyak 728 kasus disertai peningkatan IMT. Sedangkan pada laki-laki didapatkan sebanyak 1309 kasus dengan peningkatan IMT. $^{2}$

Penelitian yang dilakukan oleh Susilo tahun 2012 didapatkan hasil sebanyak 192 pasien didiagnosis kolelitiasis. Perempuan lebih banyak yaitu $67,71 \%$ daripada laki-laki $32,29 \%$. Usia tertinggi rata-rata 40 tahun $(80,46 \%)$. Pasien dengan peningkatan IMT sebanyak $69,27 \% .^{5}$

Insiden kolelitiasis di bagian bedah digestif di RSI Siti Rahmah mengalami peningkatan dalam empat tahun terakhir. Pada tahun 2014 kejadian kolelitiasis berjumlah 10 kasus, serta pada tahun 2017 berjumlah 118 kasus. ${ }^{6}$

Dari penjelasan diatas maka peneliti tertarik untuk melakukan penelitian mengenai hubungan peningkatan indeks massa tubuh dengan dengan kejadian kolelitiasis di bagian bedah digestif RSI Siti Rahmah Padang periode Januari-Juni 2018.

\section{Metode Penelitian}

Penelitian ini membahas mengenai hubungan antara peningkatan indeks massa tubuh dengan kejadian kolelitiasis di RSI Siti Rahmah Padang. Penelitian ini merupakan penelitian analitik observasional menggunakan rancangan crosssectional. Populasi penelitian ini adalah pasien bagian bedah digestif (usia $\geq 30$ tahun) instalasi bedah RSI Siti Rahmah periode Januari -Juni 2018 disertai data tinggi badan dan berat badan yang tercatat di rekam medik. Subjek penelitian diambil dengan teknik simple random sampling. Data diambil dari data sekunder yaitu data rekam medik. Analisa data yang dilakukan adalah Analisa Univariat dan Bivariat. Data disajikan dengan menghitung frekuensi distribusi, serta analisis hubungan kemudian diproses dan diolah dengan bantuan program komputer yaitu SPSS V.24

\section{HASIL}

Penelitian dilakukan di bagian bedah digestif periode Januari-Juni 2018 di RSI Siti Rahmah padang.

Tabel 1. Prevalensi Pasien Kolelitiasis Bedah DIGESTIF

\begin{tabular}{lllll}
\hline \multirow{2}{*}{ Karakteristik } & \multicolumn{2}{l}{ Populasi } & \multicolumn{2}{l}{ Sampel } \\
\cline { 2 - 5 } & $\mathrm{N}$ & $\%$ & $\mathrm{~N}$ & $\%$ \\
\hline Kolelitiasis & & & & \\
Ya & 41 & 4,63 & 19 & 43,1 \\
Tidak & 845 & 95,37 & 25 & 56,9 \\
Total & 886 & 100 & 44 & 100 \\
\hline
\end{tabular}

Berdasarkan tabel 1 diperoleh hasil 41 $(4,63 \%)$ kasus kolelitiasis dan 845 (95,37\%) non-kolelitiasis. Sampel yang digunakan 19 kolelitiasis dan 25 non-kolelitiasis. 
TABEl 2. KARAKTERISTIK DEMOGRAFI PASIEN MELIPUTI JENIS KELAMIN DI BAGIAN BEDAH Digestif Rsi Siti RahMah PAdang Periode JANUARI-JUNI 2018

\begin{tabular}{lllllll}
\hline \multirow{2}{*}{ Jenis kelamin Frekuensi } & \multicolumn{2}{l}{ Kolelitiasis } & \multicolumn{2}{l}{$\begin{array}{l}\text { Non- } \\
\text { Kolelitiasis }\end{array}$} \\
\cline { 2 - 7 } & $\mathrm{N}$ & $\%$ & $\mathrm{~N}$ & $\%$ & $\mathrm{~N}$ & $\%$ \\
\hline Laki-laki & 20 & 45,5 & 8 & 42,1 & 12 & 48 \\
Perempuan & 24 & 54,5 & 11 & 57,9 & 13 & 52 \\
Total & 44 & 100 & 19 & 100 & 25 & 100 \\
\hline
\end{tabular}

Berdasarkan tabel 2 diperoleh hasil pada kasus kolelitiasis yaitu perempuan 11 orang $(57,9 \%)$ dan laki-laki 8 orang $(42,1 \%)$. Kategori non kolelitiasis didapatkan perempuan 13 orang (52\%) dan laki-laki 12 orang $(48 \%)$.

Tabel 3. Karakteristik Demografi Pasien MELIPUTI USIa Di BAgIAN BEDAH DigeSTIF RSI Siti Rahmah Padang Periode Januari-Juni 2018

\begin{tabular}{lllllll}
\hline \multirow{2}{*}{ Usia (tahun) } & \multicolumn{2}{l}{$\begin{array}{l}\text { Frekuensi } \\
\mathbf{n = 4 4}\end{array}$} & \multicolumn{2}{l}{ Kolelitiasis } & \multicolumn{2}{l}{$\begin{array}{l}\text { Non } \\
\text { Kolelitiasis }\end{array}$} \\
\cline { 2 - 7 } & $\mathrm{n}$ & $\%$ & $\mathrm{n}$ & $\%$ & $\mathrm{n}$ & $\%$ \\
\hline $\mathbf{3 0 - 3 9}$ & 13 & 27,3 & 4 & 21,1 & 9 & 36 \\
$\mathbf{4 0 - 4 9}$ & 12 & 27,3 & 7 & 36,8 & 5 & 20 \\
$\mathbf{5 0 - 5 9}$ & 10 & 22,7 & 4 & 21,1 & 6 & 24 \\
$\mathbf{6 0 - 6 9}$ & 7 & 15,9 & 3 & 15,8 & 4 & 16 \\
$\mathbf{7 0 - 7 9}$ & 2 & 4,5 & 1 & 5,3 & 1 & 4 \\
\hline Total & 44 & 100 & 19 & 100 & 25 & 100 \\
\hline
\end{tabular}

Berdasarkan tabel 3 diperoleh hasil, proporsi usia pada kelompok usia 30-39 tahun(27,3\%) dan 40-49 tahun (27,3\%). Proporsi nonkolelitiasis tertinggi pada usia 30-39 yaitu $32 \%$ berbanding. Proporsi Kolelitiasis tertinggi pada usia 40-49 tahun yaitu 36,8\%. Frekuensi usia pasien yang paling sedikit ialah pada kelompok usia 70-79 tahun yaitu 2 orang $(4,5 \%)$.

TABEL 4. Distribusi FrekUENSI INDEKS MASSA Tubuh Pasien Di Bagian BEDAh DIgestif RSI Siti Rahmah Padang Periode Januari-Juni 2018.

\begin{tabular}{lll}
\hline Peningkatan IMT & $\boldsymbol{n}$ & \% \\
\hline Meningkat & 17 & 38,6 \\
Tidak & 27 & 61,4 \\
Jumlah & 44 & 100 \\
\hline
\end{tabular}

Berdasarkan tabel 4 diperoleh hasil, 17 $(38,6 \%)$ IMT meningkat. IMT yang tidak meningkat adalah 27 orang $(61,4 \%)$.

Tabel 5. Hubungan Peningkatan Indeks Massa TUbuh DENGan KeJadian Kolelitiasis DI BAGIAN BEDAH DIGESTIF RSI SITI RAHMAH Padang Periode Januari-Juni 2018

\begin{tabular}{llllllll}
\hline IMT & \multicolumn{3}{l}{ Kolelitiasis } & \multicolumn{3}{c}{ Total } & \multicolumn{1}{l}{$\begin{array}{l}\text { P } \\
\text { value }\end{array}$} \\
\cline { 2 - 6 } & $\mathrm{Ya}$ & \multicolumn{3}{c}{ Tidak } & & & \\
\cline { 2 - 7 } & $\mathrm{n}$ & $\%$ & $\mathrm{n}$ & $\%$ & $\mathrm{n}$ & $\%$ & 001 \\
\hline Meningkat & 13 & 76,5 & 4 & 23,5 & 17 & 100 & \\
\hline Tidak & $\mathbf{6}$ & $\mathbf{2 2 , 2}$ & $\mathbf{2 1}$ & $\mathbf{7 7 , 8}$ & $\mathbf{2 7}$ & $\mathbf{1 0 0}$ & \\
\hline
\end{tabular}

Berdasarkan tabel 5, diperoleh hasil IMT meningkat,kategori kolelitiasis 13 orang (76,5\%), sedangkan tidak kolelitiasis 4 orang $(23,5 \%)$. Pada IMT tidak meningkat, 6 $(22,25)$ kolelitiasis dan 21(77,8\%) tidak kolelitiasis. Hasil uji statistik (chi-square) diperoleh nilai $\mathrm{p}=0,001(\mathrm{p}<0,05)$.

\section{Pembahasan}

\section{A. Prevalensi Pasien Kolelitiasis}

Penelitian dengan subjek 44 sampel diperoleh sebanyak 19 kasus (43,2\%) pasien kolelitiasis. Pasien non-kolelitiasis sebanyak 25 kasus $(56,8 \%)$.

Penelitian sebelumnya yang dilakukan oleh Tuuk tahun 2016 di RSUP Prof Dr. R.D.Kandou Manado periode Oktober 2015Oktober 2016 diperoleh hasil 94 (83\%) kasus kolelitiasis dan 19 (17\%) kasus non kolelitiasis. ${ }^{7}$ Penelitian lain dilakukan oleh Tazuma et al tahun 2015 di Jepang tahun 2013 mendapatkan 74,5\% kasus kolelitiasis dan $29,3 \%$ non-kolelitiasis. ${ }^{8}$ Temuan lain oleh Taher tahun 2013 di Rumah Sakit Medis Baghdad menunjukkan proporsi jumlah kasus kolelitiasis sebanyak 75 pasien. $^{9}$

\section{B. Karakteristik Sampel}

1) Jenis Kelamin

Penelitian terhadap 44 sampel didapatkan hasil bahwa pasien kolelitiasis sebanyak 11 orang $(57,9 \%)$ adalah perempuan dan 8 
orang laki-laki $(42,1 \%)$. Sedangkan pasien non-kolelitiasis 12 orang (48\%) adalah lakilaki dan 13 (52\%) adalah perempuan.

Hasil penelitian ini sesuai dengan penelitian yang dilakukan Dani tahun 2013 di RS Immanuel Bandung 2012. Pada penelitian diperoleh hasil paling banyak pasien kolelitiasis adalah perempuan $(67,71 \%)$, sedangkan laki-laki berjumlah 62 orang $(32,29 \%){ }^{5}$

Temuan lain dilakukan oleh Stender tahun 2013 menunjukkan bahwa ditemukan 265 kasus kolelitiasis pada perempuan dan 89 kasus pada laki-laki. ${ }^{10}$ Hasil penelitian sesuai dengan teori bahwa, perempuan terutama selama waktu subur dua kali lebih memiliki resiko batu empedu dibandingkan laki-laki. Hal tersebut karena pengaruh hormon seks esterogen yang dapat meningkatkan penyerapan kolesterol makanan dan meningkatkan sekresi kolesterol empedu. ${ }^{11}$

\section{2) Usia}

Penelitian terhadap 44 sampel yang diambil didapatkan bahwa frekuensi tertinggi pada kelompok usia 30-39 tahun dan 40-49 tahun. Pasien kolelitiasis tertinggi pada kelompok usia 40-49 tahun sebanyak 7 kasus $(36,8 \%)$. Sedangkan pada non-kolelitiasis tertinggi pada usia 30-39 tahun sebanyak 9 $\operatorname{kasus}(36 \%)$.

Hasil ini sesuai dengan penelitian yang dilakukan Ulil tahun 2013 di RSUP DR Wahidin Sudirohusodo menunjukkan kasus kolelitiasis tertinggi pada usia 40-49 tahun yaitu 31 kasus $(35,63 \%) .{ }^{12}$ Hasil yang sama ditemukan pada hasil penelitian Gyedu tahun 2015, bahwa usia $\geq 40$ tahun sebesar 1737 $(61,5 \%) .{ }^{13}$ Temuan lain yang sesuai adalah penelitian Dani tahun 2012 di RS Immanuel Bandung kasus kolelitiasis tertinggi usia 4049 tahun $(33,33 \%)^{5}$

Hal ini sesuai dengan teori dimana usia 40 tahun keatas memiliki risiko tinggi terjadinya kolelitiasis karena pertambahan usia berkaitan dengan hipersekresi kolesterol, penurunan jumlah asam empedu, dan penurunan sekresi garam empedu. 11 Penelitian lain menyimpulkan ternyata usia dan diabetes menjadi faktor risiko yang signifikan dari kolelitiasis pada keduanya jenis kelamin. Faktor-faktor penting termasuk: pada pria - usia, pendidikan, ketebalan lipatan subscapular, kadar kolesterol HDL yang tinggi; di wanita - usia, BMI, ketebalan lipatan kulit, diabetes, gangguan toleransi glukosa dan kontrasepsi oral. ${ }^{14}$

\section{Peningkatan Indeks Massa Tubuh}

Kegemukan dan obesitas didefinisikan sebagai lemak yang abnormal atau berlebihan akumulasi yang dapat merusak kesehatan. Indeks massa tubuh (IMT) adalah indeks sederhana dan ukuran yang diterima digunakan untuk membedakan berat badan berlebih, termasuk kelebihan berat badan dan obesitas. $^{15}$

Saat ini semakin meningkatnya tuntutan pekerjaan dan kebutuhan hidup setiap orang, membuat masyarakat Indonesia melakukan gaya hidup yang tidak sehat. Meningkatnya konsumsi makanan tinggi kalori dan tinggi lemak, waktu melakukan latihan fisik yang terbatas, dan adanya stress. ${ }^{16}$ Banyak faktor yang menyebabkan terjadinya kolelitiasis, mulai dari usia, jenis kelamin, berat badan berlebih dan obesitas, serta gaya hidup masyarakat saat ini.

Berdasarkan penelitian yang telah dilakukan diperoleh hasil dari 44 sampel diperoleh hasil, $17(38,6 \%)$ IMT meningkat. IMT yang tidak meningkat adalah 27 orang $(61,4 \%)$. Hasil penelitian menunjukkan frekuensi peningkatan IMT pada kolelitiasis lebih tinggi dari non-kolelitiasis.

Hasil ini sesuai dengan penelitian Jethro tahun 2016, bahwa frekuensi peningkatan IMT pada pasien kolelitiasis lebih tinggi dari sampel non-kolelitiasis yaitu $16 \quad(21,1 \%)$ berbanding $5(6,6 \%) .{ }^{17}$ Penelitian lain yang sesuai adalah penelitian yang dilakukan 
Kharga tahun 2015 dengan hasil frekuensi peningkatan IMT lebih tinggi pada kelompok kolelitiasis yaitu 650 orang dan kelompok non-kolelitiasis berjumlah 234 orang. ${ }^{18}$

\section{Hubungan Peningkatan IMT dengan Kolelitiasis}

Individu dengan berat badan berlebih dan obesitas yang mengkonsumsi makanan tinggi kalori dapat membuat terganggunya pengosongan kandungan empedu. Hal tersebut membuat terganggunya motilitas kandung empedu, sehingga terjadi pengendapan. Dimana pada orang dengan berat badan berlebih dan obesitas, kadar kolesterol meningkat. Obesitas akan meningkatkan risiko batu empedu kolesterol dengan meningkatkan sekresi kolesterol empedu, sebagai hasil peningkatan aktivitas reduktase koenzim A-2 hidroksi-3 mthilglutaryl (HMGCoA). ${ }^{18}$

Hasil penelitian menunjukkan hubungan yang bermakna antara peningkatan IMT terhadap kejadian kolelitiasis dengan nilai $p$ yaitu 0,001 dengan odds ratio sebesar 11,375. Hasil pada IMT meningkat terbanyak pada pasien kolelitiasis yaitu 13 orang $(76,5 \%)$ dan IMT tidak meningkat lebih banyak pada non-kolelitiasis yaitu 21 orang $(77,8 \%)$.

Penelitian ini sesuai dengan penelitian yang dilakukan Festi et al tahun 2008, bahwa terdapat hubungan IMT yang meningkat terhadap kolelitiasis di Italia dengan nilai $p=0,0195 \quad(<0.05) .{ }^{19}$ Temuan lain dari penelitian Zhu tahun 2014 pada pasien kolelitiasis dengan IMT rata-rata 26-27 $\mathrm{kg} / \mathrm{m}^{2}$, didapatkan hasil analisis dengan nilai $p=0,006 \quad(p=<0,05) .^{20}$ Penelitian lain di Taiwan yang dilakukan Hung et al tahun 2011 juga menunjukkan adanya hubungan antara peningkatan IMT terhadap peningkatan risiko kolelitiasis dengan nilai $p=0,008$ dan $\mathrm{OR}=1,89 .^{21}$

Peningkatan IMT telah dikaitkan dengan peningkatan volume residu setelah kontraksi kandung empedu, gangguan kontraktilitas, dan mengurangi sensitivitas terhadap kolesistokinin, yang biasanya merangsang kontraksi kandung empedu, semuanya mendukung stasis empedu dan pembentukan batu empedu. ${ }^{22}$

\section{KESIMPUlan DAN SARAN}

1. Prevalensi kolelitiasis di bedah digestif RSI Siti Rahmah padang pada bulan januari-juni 2018 yaitu 4,63\%. .

2. Penderita kolelitiasis terbanyak di bagian bedah digestif RSI Siti Rahmah Padang periode januari-juni 2018 adalah perempuan.

3. Angka kejadian kolelitiasis di bagian bedah digestif RSI Siti Rahmah Padang periode januari-juni 2018 paling banyak ditemukan pada kelompok usia 40-49 tahun.

4. Semakin tinggi nilai Indeks Massa Tubuh (IMT), maka semakin besar resiko terjadinya kolelitiasis.

5. Terdapat hubungan antara peningkatan IMT dengan kejadian kolelitiasis di bagian bedah digestif RSI Siti Rahmah Padang periode Januari-Juni 2018 dengan nilai $\mathrm{p}=0,001(\mathrm{p}<0,05)$.

\section{DAfTAR Pustaka}

[1] Sioka E, Zacharoulis D, Zachari E, Papamargaritis D, Pinaka O, Katsogridaki G, et al. Complicated Gallstones after Laparoscopic Sleeve Gastrectomy. 2014.

[2] Liu T, Wang W, Ji Y, Wang Y, Liu X, Cao L, et al. Association Between Different Combination of Measures for Obesity and New-onset Gallstone Disease. 2018;63:1-11.

[3] Kim SB, Kim KH, Kim TN, Heo J, Jung MK, Cho CM, et al. Sex Differences in Prevalence and Risk Factors of Asymptomatic Cholelithiasis in Korean Health Screening Examinee.2017:1-7.

[4] Ginting S A. Description Characteristic Risk Factor of The Kolelitiasis Disease in The Columbia Asia Medan Hospital. Journal Darma Agung. 2011;38-45.

[5] Dani, Susilo L . Karakteristik Pasien Cholelithiasis di Rumah Sakit Immanuel Bandung Periode 1 Januari 2012 - 31 Desember 2012. Fakultas Kedokteran Universitas Kristen Maranatha . 2012. 
Heme, Vol I No 2

July 2019

[6] RSI Siti Rahmah Padang. Laporan Rekam Medik Pasien Instalasi Bedah tahun 2014-2017. Padang: RSI Siti Rahmah Padang;2018.

[7] Tuuk ALZ, Noersasongko AD. Profil kasus batu empedu di RSUP Prof . Dr . R . D . Kandou Manado Jimmy Panelewen. 2016;4:2-7.

[8] Tazuma S, Kanno K, Kubota K, Tsuyuguchi T, Kamisawa T, Isayama H. Report on the 2013 national cholelithiasis survey in Japan. 2015;(August 2013):392-5.

[9] Taher MA. Descriptive study of cholelithiasis with chemical constituents' analysis of gallstones from patients living in Baghdad, Iraq. nternational J Medi cine Med Sci ences [Internet]. 2013;5(1):19-2 3. Available from: http://www.academicjournals.org/journal/IJMMS /article-full-textpdf/AAA17FF 292

[10] Stender S, Nordestgaard BG, Tybjaerg-Hansen A. Elevated Body Mass Index as a Causal Risk Factor for Symptomatic Gallstone Disease: Amendelian Randomization Study. American Association for the Study of Liver Disease. 2013; 58(6):2133-2141.

[11] Stinton LM, Shaffer EA. Epidemiology of Gallbladder Disease : Cholelithiasis and Cancer. 2012;6(2):172-87.

[12]Ulil A A. Karakteristik Pasien Kolelitiasis Di RSUP DR Wahidin Sudirohusodo Makassar Periode Januari-Desember 2012 Fakultas Kedokteran Universitas Hassanudin: Makassar. 2013.

[13] Gyedu A, Adae-aboagye K, Badu-peprah A, Anokye K, Hospital T, Anokye K, et al. Prevalence of cholelithiasis among persons undergoing abdominal ultrasound at the Komfo Anokye Teaching Hospital, Kumasi , Ghana . 2015;15(1):247-50.

[14] Ostrowska L, Czapska D, Jk K. Body weight gain as the major risk factor of cholelithiasis in women and an important risk factor in man. 2005;50:546.

[15] Hebebrand J, Holm J, Woodward E, Baker JL, Blaak E, Schutz DD, et al. A Proposal of the European Association for the Study of Obesity to Improve the ICD-11 Diagnostic Criteria for Obesity Based on the Three Dimensions Etiology , Degree of Adiposity and Health Risk. 2017;284-307.

[16] Tjokroprawiro. A. Garis Besar Pola Makan dan Pola Hidup Sebagai Pendukung Terapi DiabetesMellitus. Surabaya: Fakultas Kedokteran Unair.2012.

[17] Jethro E S. Hubungan Status Gizi dan Jenis Kelamin dengan Kejadian Kolelitiasis Pada Pasien Rawat Inap di Bagian Bedah RSUP. Dr. Muhammad Hoesin Palembang. Fakultas Kedokteran Universitas Sriwijaya.2016.

[18] Kharga B, Sharma BK, Singh VK, Nishant K. Obesity Not Necessary, Risk of Symptomatic
Cholelithiasis Increases as a Function of BMI. 2016;(December 2015):28-32.

[19] Festi D, Dormi A, Capodicasa S, Staniscia T, Attili AF, Loria P, et al. Incidence of gallstone disease in Italy: results from a multicenter, population- based Italian study ( the MICOL project ) Incidence of gallstone disease in Italy : Results from a multicenter, population-based Italian study (the MICOL project ). 2008;(June 2014).

[20]Zhu L, Aili A, Zhang C, Saiding A, Abudureyimu K. Prevalence of and risk factors for gallstones in Uighur and Han Chinese. 2014;20(40):14942-9.

[21]Hung S, Liao K, Lai S, Li C, Chen W. Risk Factors Associated with Symptomatic Cholelithiasis in Taiwan: a Population-based Study. BMC Gastroenterol [Internet]. 2011;11(1):111. Available from: http://www.biomedcentral.com/1471230X/11/111.

[22] Shabanzadeh DM, Sørensen LT, Jørgensen T. Determinants for gallstone formation - a new data cohort study and a systematic review with meta- analysis *. 2016;5521(November).

Email : heme@unbrah.ac.id 